Check for updates

Cite this: Chem. Sci., 2019, 10, 7773

๑ All publication charges for this article have been paid for by the Royal Society of Chemistry

Received 30th May 2019

Accepted 28th June 2019

DOI: $10.1039 / c 9 s c 02633 a$

rsc.li/chemical-science

\section{Ultralong room-temperature phosphorescence of a solid-state supramolecule between phenylmethylpyridinium and cucurbit[6]uril $\uparrow$}

\author{
Zhi-Yuan Zhang (DD) and Yu Liu (D) *
}

Long-lived organic room-temperature phosphorescence (RTP) has received great attention because of its various potential applications. Herein, we report a persistent RTP of a solid-state supramolecule between a cucurbit[6]uril (CB[6]) host and a heavy-atom-free phenylmethylpyridinium guest. Significantly, the long-lived phosphorescence completely depends on the host-guest complexation, revealing that the non-phosphorescent guest exhibits a $2.62 \mathrm{~s}$ ultralong lifetime after being complexed by CB[6] under ambient conditions. The ultralong RTP is because of tight encapsulation of CB[6], which boosts intersystem crossing, suppresses nonradiative relaxation and possibly shields quenchers. Moreover, several phosphorescent complexes possessing different lifetimes are prepared and successfully applied in triple lifetime-encoding for data encryption and anti-counterfeiting. This strategy provides a new insight for realizing purely organic RTP with ultralong lifetime and expands its application in the field of information protection

\section{Introduction}

Organic room-temperature phosphorescence (RTP) with persistent luminescence has received enormous attention because of its various applications in biological imaging, ${ }^{1,2}$ light-emitting devices, ${ }^{3}$ information storage and encryption, ${ }^{4,5}$ and so on. However, achieving ultralong RTP (generally from seconds to hours) is extremely difficult due to two main issues: (i) the intrinsically weak spin-orbit coupling of purely organic molecules makes it hard to achieve efficient intersystem crossing (ISC); (ii) a long triplet state $\left(\mathrm{T}_{1}\right)$ lifetime means that $\mathrm{T}_{1}$ will suffer tremendously from quenching by a very low concentration of impurities even in crystals. ${ }^{6}$ Several methods have been reported to actualize long-lived RTP, such as forming charge-separated states, ${ }^{7}$ crystallization, ${ }^{8-17}$ polymerization, ${ }^{18-21}$ embedding into suitable matrices, ${ }^{22-24}$ and so on. ${ }^{25-27}$ Recently, Huang and co-workers achieved lifetimes of $1.35 \mathrm{~s}$ and $1.91 \mathrm{~s}$ by reasonable crystal design. ${ }^{28,29}$ Fukushima and Nakai et al. found that the lifetime of arylboronic esters in crystals could reach $1.85 \mathrm{~s}$ due to an appropriate molecular packing. ${ }^{30}$ Zhao and coworkers reported ultralong RTP with a lifetime of $0.75 \mathrm{~s}$ by embedding phosphors into polymers. ${ }^{31}$ Tian and co-workers developed purely organic amorphous polymers with a lifetime of $0.537 \mathrm{~s}$ by utilizing hydrogen-bonding networks between polymeric chains, and prepared cyclodextrin based

Department of Chemistry, State Key Laboratory of Elemento-Organic Chemistry, Nankai University, Tianjin 300071, P. R. China. E-mail: yuliu@nankai.edu.cn

$\dagger$ Electronic supplementary information (ESI) available. See DOI: $10.1039 / \mathrm{c} 9 \operatorname{sc} 02633 \mathrm{a}$ phosphors. ${ }^{32-34} \mathrm{Wu}$ and co-workers reported self-assembled nanoparticles with RTP for cell imaging. ${ }^{35}$ Besides, theoretical descriptors were also utilized to assist in the molecular design of efficient and long-lived RTP. ${ }^{36}$

More recently, we found that the phosphorescence quantum yield of bromophenyl-methyl-pyridinium chloride (PYCl) could reach $81.2 \%$ after being complexed by cucurbit[6]uril $(\mathrm{CB}[6]){ }^{37}$ In general, the introduction of heavy atoms facilitates ISC and thus contributes to high phosphorescence quantum yield, but the heavy atoms will result in a shorter lifetime (normally below a millisecond) because of the acceleration of radiative and nonradiative decay rates of the triplet state. ${ }^{6}$ The high efficiency and short lifetime ( $\tau=5.40 \mathrm{~ms}$ ) of the complex (PYCl/CB[6]) in our recent work is a typical case ${ }^{37}$ Therefore, removing a heavy atom $(\mathrm{Br})$ from $\mathrm{PYCl}$ will slow down radiative and non-radiative decay of the triplet state and probably achieve long-lived RTP. It is reasonable to realize this proposal by a solid-state supramolecular strategy because the aforementioned issues in achieving ultralong RTP will no longer exist: firstly, the encapsulation of $\mathrm{CB}[6]$ promotes ISC of the guest and thus boosts the production of triplet states, which will (partially) offset the absence of the heavy atom; secondly, the extreme restriction of the guest by $\mathrm{CB}[6]$ will greatly suppress molecular motions (vibrations, rotations, and inter-collisions) and prolong the lifetime of phosphorescence; thirdly, $\mathrm{CB}[6]$ will act as a fine shell to prevent quenchers (oxygen, impurities and so on) from attacking triplet states. To verify our hypothesis, phenylmethylpyridinium chloride ( $\mathrm{PBC}$ ) was designed and synthesized. Furthermore, a series of derivatives were prepared to explore the generalizability of the solid-state supramolecular 

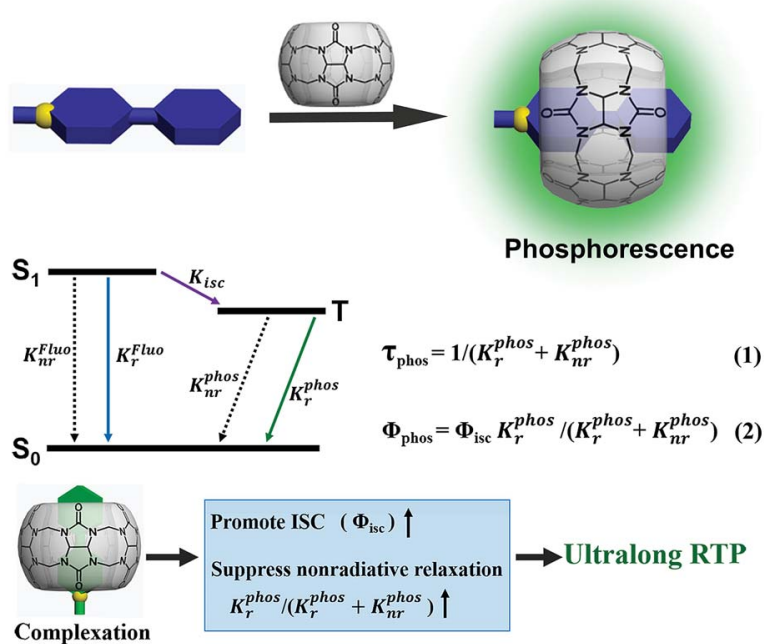

Complexation

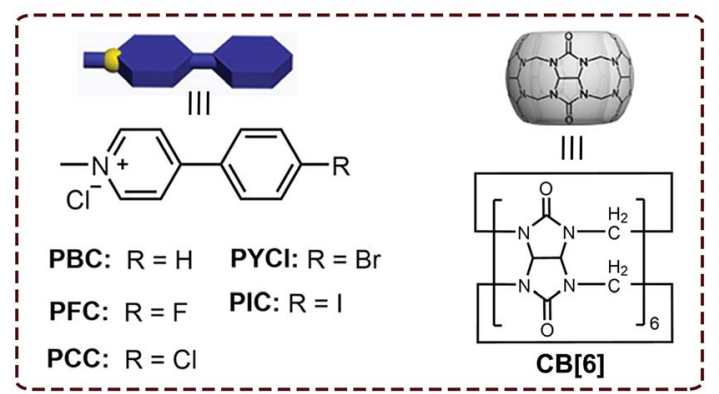

Scheme 1 Schematic illustration of the solid-state supramolecular strategy and Jablonski diagram for radiative and non-radiative processes. ( $K_{r}^{\text {Fluo }}$ is the radiative rate constant of the lowest excited singlet state $\mathrm{S}_{1} ; K_{\mathrm{nr}}^{\mathrm{Fluo}}$ is the nonradiative rate constant of the lowest excited singlet $\mathrm{S}_{1} ; K_{\text {isc }}$ is the intersystem crossing rate constant from the excited singlet state to the triplet state; $K_{r}^{\text {Phos }}$ is the radiative rate constant of the lowest excited triplet state $\mathrm{T}_{1} ; K_{\mathrm{nr}}^{\mathrm{Phos}}$ is the nonradiative rate constant of the lowest excited triplet state $T_{1} ; \tau_{\text {Phos }}$ is the lifetime of the excited triplet state; $\Phi_{\text {Phos }}$ is the quantum yield of phosphorescence; and $\Phi_{\text {isc }}$ is the quantum yield of intersystem crossing from the excited singlet state to the triplet state; inset: the molecular structures of the guests and host).

strategy and uncover the relationship between the structure of guests and the phosphorescence properties of complexes (Scheme 1 and Fig. S1-S14†).

\section{Experimental}

\section{Materials and methods}

All chemicals were commercially available unless noted otherwise. NMR spectroscopy was performed on a Bruker AV400 spectrometer. XRD patterns obtained at Rigaku SmartLab $3 \mathrm{~kW}$. High-resolution mass spectrometry (HR-MS) was performed on a Q-TOF LC-MS in ESI/MALDI mode. Photoluminescence spectra and lifetimes were measured on an FLS900 and FLS1000. Phosphorescence quantum efficiencies were measured on a HAMAMATSU C9920-02.

\section{Synthesis of PX}

Compound PBC was synthesized according to the literature. ${ }^{38} 4$ Phenylpyridine (1.09 g, $5.85 \mathrm{mmol}$ ) and methyl iodide ( $2 \mathrm{~mL}, 30$ mmol) were dissolved in anhydrous ethanol $(50 \mathrm{~mL})$ and then heated under reflux for $24 \mathrm{~h}$. After being cooled to room temperature, the reaction mixture was concentrated and the resulting pale gold precipitate was washed with dichloromethane and then dried under vacuum to yield a pale gold solid (1.32 $\mathrm{g}, 76 \%)$. After dispersing the solid in $30 \mathrm{~mL}$ acetonitrile, saturated aqueous $\mathrm{NH}_{4} \mathrm{PF}_{6}$ was added until all of the solid dissolved. After evaporating the acetonitrile and filtering, a white solid was obtained. After dissolving the solid in $\mathrm{CH}_{3} \mathrm{CN}$, tetrabutylammonium chloride was added until no solid appeared any more. PBC (white solid) was obtained after filtering and washing with $\mathrm{CH}_{3} \mathrm{CN}(10 \mathrm{~mL} \times 3) .{ }^{1} \mathrm{H}$ NMR $(400 \mathrm{MHz}, \mathrm{DMSO}) \delta 9.12(\mathrm{~d}, J$ $=6.2 \mathrm{~Hz}, 2 \mathrm{H}), 8.53(\mathrm{~d}, J=6.3 \mathrm{~Hz}, 2 \mathrm{H}), 8.09(\mathrm{~d}, J=5.6 \mathrm{~Hz}, 2 \mathrm{H})$, $7.64(\mathrm{~d}, J=5.8 \mathrm{~Hz}, 3 \mathrm{H}), 4.38$ (s, 3H); ${ }^{13} \mathrm{C} \mathrm{NMR}(101 \mathrm{MHz}, \mathrm{DMSO})$ $\delta$ 154.16, 145.68, 133.54, 131.99, 129.64, 128.05, 124.06, 46.96.

Compound PFC was synthesized according to the literature. ${ }^{38}$ Cesium carbonate $(0.98 \mathrm{~g}, 3.0 \mathrm{mmol})$ and tetrakis(triphenylphosphine)palladium $(0.23 \mathrm{~g}, 0.20 \mathrm{mmol})$ were added to a stirred solution of 4-bromopyridine hydrochloride $(0.49 \mathrm{~g}$, $2.5 \mathrm{mmol}$ ) and 4-fluorobenzeneboronic acid (0.42 g, $3.0 \mathrm{mmol})$ in dioxane/methanol $(125 \mathrm{~mL})$. The mixture was heated under reflux for $24 \mathrm{~h}$ and then concentrated. The slurry was triturated with ethyl acetate $(40 \mathrm{~mL})$ and the organic phase was washed with saturated aqueous sodium bicarbonate $(30 \mathrm{~mL} \times 3)$, water $(30 \mathrm{~mL} \times 2)$, and brine $(100 \mathrm{~mL})$, and then dried over sodium sulfate. After removal of the solvent by evaporation, the resulting residue was subjected to column chromatography (petroleum ether/ethyl acetate $8: 1$ ) to give a white solid. Then the solid reacted with methyl iodide and was purified in a similar manner to PBC. After ion exchange, PFC was obtained as a white solid. ${ }^{1} \mathrm{H}$ NMR (400 MHz, $\left.\mathrm{D}_{2} \mathrm{O}\right) \delta 8.69(\mathrm{~d}, J=6.5 \mathrm{~Hz}, 2 \mathrm{H}), 8.16$ (d, $J=6.5 \mathrm{~Hz}, 2 \mathrm{H}), 7.88(\mathrm{dd}, J=8.6,5.3 \mathrm{~Hz}, 2 \mathrm{H}), 7.28(\mathrm{t}, J=8.7 \mathrm{~Hz}$, $2 \mathrm{H}), 4.32(\mathrm{~s}, 3 \mathrm{H}) ;{ }^{13} \mathrm{C}$ NMR (101 MHz, $\left.\mathrm{D}_{2} \mathrm{O}\right) \delta$ 166.16, 163.66, 154.96, 144.81, 130.35, 124.44, 116.75, 47.17; HRMS $(\mathrm{m} / \mathrm{z})$ : [M$\mathrm{Cl}]^{+}$calcd for $\mathrm{C}_{12} \mathrm{H}_{11} \mathrm{NF}^{+}$, 188.0875; found, 188.0874 .

Compound PCC was prepared as a white powder according to a procedure similar to that described for compound PBC: ${ }^{1} \mathrm{H}$ NMR (400 MHz, DMSO) $\delta 9.10(\mathrm{~d}, J=6.8 \mathrm{~Hz}, 2 \mathrm{H}), 8.54(\mathrm{~d}, J=6.9$ $\mathrm{Hz}, 2 \mathrm{H}), 8.13(\mathrm{~d}, J=8.6 \mathrm{~Hz}, 2 \mathrm{H}), 7.72(\mathrm{~d}, J=8.6 \mathrm{~Hz}, 2 \mathrm{H}), 4.36$ (s, $3 \mathrm{H}) ;{ }^{13} \mathrm{C}$ NMR (101 MHz, DMSO) $\delta$ 152.92, 145.77, 137.12, 132.42, 129.96, 129.69, 124.13, 47.08.

Compound PIC was prepared as a pale yellow powder according to a procedure similar to that described for compound PFC: ${ }^{1} \mathrm{H}$ NMR $\left(400 \mathrm{MHz}, \mathrm{D}_{2} \mathrm{O}\right) \delta 8.70(\mathrm{~d}, J=6.5 \mathrm{~Hz}$, $2 \mathrm{H}), 8.15(\mathrm{~d}, J=6.5 \mathrm{~Hz}, 2 \mathrm{H}), 7.89(\mathrm{~d}, J=8.4 \mathrm{~Hz}, 2 \mathrm{H}), 7.55$ (d, $J=$ $8.4 \mathrm{~Hz}, 2 \mathrm{H}), 4.33(\mathrm{~s}, 3 \mathrm{H}) ;{ }^{13} \mathrm{C}$ NMR (101 MHz, $\left.\mathrm{D}_{2} \mathrm{O}\right) \delta 154.96$, 144.92, 138.72, 133.03, 129.22, 124.38, 98.87, 47.33; HRMS ( $\mathrm{m} / \mathrm{z})$ : $[\mathrm{M}-\mathrm{Cl}]^{+}$calcd for $\mathrm{C}_{12} \mathrm{H}_{11} \mathrm{NI}^{+}$, 295.9936; found, 295.9934 .

Compound PEC: ${ }^{1} \mathrm{H}$ NMR (400 MHz, DMSO) $\delta 8.93$ (d, $J=6.8$ $\mathrm{Hz}, 2 \mathrm{H}), 8.26$ (d, $J=6.8 \mathrm{~Hz}, 2 \mathrm{H}), 8.05$ (d, $J=16.4 \mathrm{~Hz}, 1 \mathrm{H}), 7.76$ $(\mathrm{d}, J=6.8 \mathrm{~Hz}, 2 \mathrm{H}), 7.59-7.42(\mathrm{~m}, 4 \mathrm{H}), 4.28(\mathrm{~s}, 3 \mathrm{H}) ;{ }^{13} \mathrm{C} \mathrm{NMR}(101$ MHz, DMSO) $\delta 152.43,145.20,140.58,135.18,130.39,129.14$, 128.12, 123.59, 123.36, 46.89.

Compound PC: ${ }^{1} \mathrm{H}$ NMR (400 MHz, DMSO) $\delta 9.13(\mathrm{~d}, J=$ $5.8 \mathrm{~Hz}, 2 \mathrm{H}), 8.59(\mathrm{t}, J=7.8 \mathrm{~Hz}, 1 \mathrm{H}), 8.15(\mathrm{t}, J=7.1 \mathrm{~Hz}, 2 \mathrm{H})$, $4.41(\mathrm{~s}, 3 \mathrm{H}) ;{ }^{13} \mathrm{C} \mathrm{NMR}(101 \mathrm{MHz}, \mathrm{DMSO}) \delta 145.66,145.05$, 127.67, 47.81 . 


\section{Results and discussion}

Using this strategy, we successfully realized ultralong RTP. The chromophore PBC itself emitted only blue fluorescence $\left(\lambda_{\max }=\right.$ $441 \mathrm{~nm}$ ) with a lifetime $(\tau)$ of $2.25 \mathrm{~ns}$ (Fig. S15†). Notably, after forming the $\mathrm{PBC} / \mathrm{CB}[6]$ complex by a grinding method, ${ }^{37}$ the solid emitted a delayed luminescence $\left(\lambda_{\max }=510 \mathrm{~nm}\right)$ with an ultralong phosphorescence of $2.62 \mathrm{~s}$, along with fluorescence at $\lambda_{\max }=427 \mathrm{~nm}(\tau=8.40 \mathrm{~ns})$ (Fig. $1 \mathrm{a}, \mathrm{b}$ and S16 $)$. And the afterglow could last more than $9 \mathrm{~s}$ after turning off the UV lamp (Fig. 1c and Video $1 \dagger$ ). This excellent long luminescence verified our hypothesis that the removal of the heavy atom could prolong the lifetime of the complex and demonstrated that the complexation of $\mathrm{CB}[6]$ could "turn on" the phosphorescence of PBC. Furthermore, the decent phosphorescence quantum yield $(9.7 \%)$ indicated that the encapsulation of $\mathrm{CB}[6]$ promoted ISC of the guest even without the assistance of the heavy atom (Table 1 and Fig. S17b $\dagger$ ). Indeed, the intersystem crossing rate $\left(K_{\text {isc }}\right)$ was as high as $1.2 \times 10^{7} \mathrm{~s}^{-1}$. Considering that there was no heavy atom to promote ISC, the result, which was only one magnitude smaller than that of $\mathrm{PYCl} / \mathrm{CB}[6](2.2 \times$ $10^{8} \mathrm{~s}^{-1}$ ), was satisfactory. Significantly, the radiative decay rate of phosphorescence $\left(K_{\mathrm{r}}^{\text {Phos }}\right)$ was very low $\left(3.7 \times 10^{-2} \mathrm{~s}^{-1}\right)$, about 4000-fold lower than that of PYCl/CB[6] $\left(150 \mathrm{~s}^{-1}\right)$, revealing that the absence of the heavy atom would slow down the decay of $T_{1}$ and favor long lifetimes. Normally, a long $T_{1}$ lifetime means that $T_{1}$ will suffer tremendously from quenching by a very low concentration of impurities because of triplet energy migration, so that extremely pure samples and complete exclusion of oxygen are needed in order to observe ultralong RTP. ${ }^{6}$ However, these rigorous conditions were no longer necessary in our case; the $\mathrm{PBC} / \mathrm{CB}[6]$ powder showed quite robust persistent RTP even upon being exposed to ambient conditions. Two reasons were proposed for this property: (i) $\mathrm{CB}$
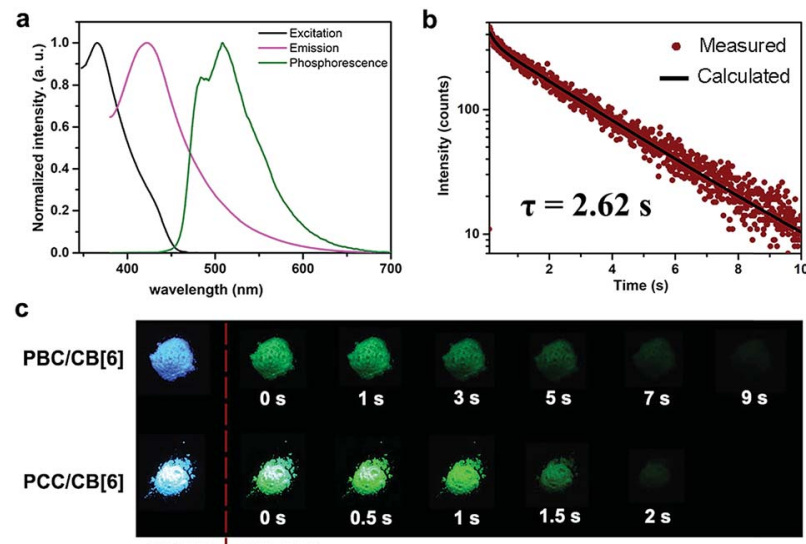

UV ON

Fig. 1 Photophysical properties of PX/CB[6]. (a) Excitation (black), photoluminescence (magenta) and phosphorescence spectra (olive) of $\mathrm{PBC} / \mathrm{CB}[6]$ in the solid state; (b) time resolved $\mathrm{PL}$ decay of $\mathrm{PBC} / \mathrm{CB}$ [6] at $510 \mathrm{~nm}$ in the solid state at room temperature; (c) luminescence photographs of $\mathrm{PBC} / \mathrm{CB}[6]$ and $\mathrm{PCC} / \mathrm{CB}[6]$ powder under $365 \mathrm{~nm}$ UV irradiation and at different time intervals after removal of the ultraviolet lamp.
[6] played the role of a tight shell to prevent quenchers (oxygen, impurities and so on) from attacking the chromophoric core (PBC); (ii) every PBC molecule possessed an individual microcircumstance provided by $\mathrm{CB}[6]$. The large outer diameter $(14.4$ $\AA)^{39}$ and high rigidity of $\mathrm{CB}[6]$ made each complex an independent phosphor unit. Possible defects (empty $\mathrm{CB}[6]$ or free PBC) would not produce serious triplet energy migration and therefore had little effect on the whole phosphorescence. They jointly stabilized the triplet state and guaranteed the robust persistent RTP.

The complex was further characterized by ${ }^{1} \mathrm{H}$ NMR, which revealed that methyl protons $H_{\mathrm{a}}$ and the aromatic protons $H_{\mathrm{b}}$, and $H_{\mathrm{e}, \mathrm{f}}$ of PBC underwent enormous upfield shifts of 0.15 , 0.29 and $0.26 \mathrm{ppm}$, respectively (Fig. 2a). These complexationinduced shifts indicated that PBC was deeply encapsulated into the cavity of $\mathrm{CB}[6]$. High resolution mass spectrometry also proved the formation of the $\mathrm{PBC} / \mathrm{CB}[6]$ complex (Fig. 2b). The intense peak of $[\mathrm{M}-\mathrm{Cl}]^{+}(\mathrm{m} / z$ 1166.3912) fitted well with the calculated value (1166.3914). The powder X-ray diffraction (XRD) pattern of the $\mathrm{PBC} / \mathrm{CB}[6]$ complex revealed its ordered array like that of $\mathrm{PYCl} / \mathrm{CB}[6]$ (Fig. 2c). The XRD peaks with $d$ spacings of 5.58 and $3.84 \AA$ were indexed to diffractions from the (220) and (330) planes, respectively. The $d$-spacings of 7.00, $4.44,3.51$, and $3.27 \AA$ were assigned to (020), (400), (040), and (240) planes (Fig. 2c). Taking into account the extremely similar structures of $\mathrm{PBC}$ and $\mathrm{PYCl}$, this result was reasonable. To verify if the arrangement of the complex influences the lifetime, we further ground the complex powder. The XRD patterns revealed that many peaks became weaker and some even disappeared, indicating the loss of order (Fig. S18a†). But the nearly identical lifetimes (2.61 s and $2.62 \mathrm{~s}$ ) confirmed that the change in the microstructure had little effect on the phosphorescence of the complex, which further proved the aforementioned proposal that each complex was an individual phosphor and the phosphorescence originated from complexation (Fig. S18b†).

We then synthesized guests with halogen atoms (F, Cl and I) possessing different coupling abilities to explore the relationship between the structure of the guests and the phosphorescence properties of the complexes. Besides, methyl-pyridinium chloride (PC) and styryl-methyl-pyridinium chloride (PEC) were also synthesized to verify whether the structure of phenylmethylpyridinium was necessary for generating phosphorescence (Scheme 1). Interestingly, the $\mathrm{PFC} / \mathrm{CB}[6], \mathrm{PCC} / \mathrm{CB}[6]$ and PIC/CB[6] complexes emitted phosphorescence peaks at $520 \mathrm{~nm}(\tau=0.0095 \mathrm{~ms}), 500 \mathrm{~nm}(\tau=275 \mathrm{~ms})$ and $575 \mathrm{~nm}$ ( $\tau=1.40 \mathrm{~ms}$ ), accompanied by strong fluorescence emission peaks at $434 \mathrm{~nm}$ ( $\tau=5.61 \mathrm{~ns}), 420 \mathrm{~nm}(\tau=2.52 \mathrm{~ns})$ and $477 \mathrm{~nm}$ ( $\tau=1.53 \mathrm{~ns}$ ) in the solid state (Table 1 and Fig. S19-S21†). In contrast, guests only showed fluorescence peaks at $443 \mathrm{~nm}$ ( $\tau=10.62 \mathrm{~ns})$ for PFC, $434 \mathrm{~nm}(\tau=3.49 \mathrm{~ns})$ for PCC and $505 \mathrm{~nm}$ ( $\tau=1.20 \mathrm{~ns}$ ) for PIC (Fig. S22 $\dagger$ ). These results proved the universality of the solid-state supramolecular strategy and indicated that the phosphorescence properties of the complex could be tuned by substituents. When the aromatic moieties were separated (PEC) or broken (PC), no phosphorescence occurred in the monomer (PEC and PC) or the complex (PEC/ 
Table 1 Photophysical data of PX/CB[6]

\begin{tabular}{|c|c|c|c|c|c|c|c|c|c|c|c|c|}
\hline Compound & $\mathrm{E}_{\mathrm{X}}(\mathrm{nm})$ & $\begin{array}{l}\lambda_{\text {Fluo }} \\
\text { (nm) }\end{array}$ & $\begin{array}{l}\lambda_{\text {Phos }} \\
(\mathrm{nm})\end{array}$ & $\tau_{\text {Fluo }}(\mathrm{ns})$ & $\tau_{\text {Phos }}(\mathrm{ms})$ & $\begin{array}{l}\Phi_{\text {Fluo }} \\
(\%)\end{array}$ & $\begin{array}{l}\Phi_{\text {Phos }} \\
(\%)\end{array}$ & $K_{\mathrm{r}}^{\text {Fluo } a}\left(\mathrm{~s}^{-1}\right)$ & $K_{\mathrm{nr}}^{\mathrm{Fluob}}\left(\mathrm{s}^{-1}\right)$ & $K_{\mathrm{isc}}{ }^{c}\left(\mathrm{~s}^{-1}\right)$ & $K_{\mathrm{r}}^{\mathrm{Phos} d}\left(\mathrm{~s}^{-1}\right)$ & $K_{\mathrm{nr}}^{\mathrm{Phose} e}\left(\mathrm{~s}^{-1}\right)$ \\
\hline $\mathrm{PBC} / \mathrm{CB}[6]$ & 366 & 427 & 510 & 8.40 & 2620 & 17.3 & 9.7 & $2.1 \times 10^{7}$ & $8.7 \times 10^{7}$ & $1.2 \times 10^{7}$ & $3.7 \times 10^{-2}$ & 0.34 \\
\hline $\mathrm{PCC} / \mathrm{CB}[6]$ & 370 & 420 & 500 & 2.52 & 275 & 41.8 & 26.7 & $1.6 \times 10^{8}$ & $1.2 \times 10^{8}$ & $1.1 \times 10^{8}$ & 0.97 & 2.7 \\
\hline $\mathrm{PYCl} / \mathrm{CB}[6]$ & 334 & 388 & 500 & 3.62 & 5.40 & 3.7 & 81.2 & $1.0 \times 10^{7}$ & $4.2 \times 10^{7}$ & $2.2 \times 10^{8}$ & 150 & 34.8 \\
\hline $\mathrm{PIC} / \mathrm{CB}[6]$ & 407 & 477 & 575 & 1.53 & 1.40 & 2.6 & 3.9 & $1.7 \times 10^{7}$ & $6.1 \times 10^{8}$ & $2.5 \times 10^{7}$ & 27.9 & $6.9 \times 10^{2}$ \\
\hline
\end{tabular}

${ }^{a}$ The radiative decay rate constant of fluorescence $K_{\mathrm{r}}^{\text {Fluo }}=\Phi_{\text {Fluo }} / \tau_{\text {Fluo }} \cdot{ }^{b}$ The nonradiative decay rate constant of fluorescence $K_{\mathrm{nr}}^{\text {Fluo }}=\left(1-\Phi_{\text {Fluo }}-\right.$ $\left.\Phi_{\text {Phos }}\right) / \tau_{\text {Fluo }}{ }^{c}$ The intersystem crossing rate constant $K_{\text {isc }}=\Phi_{\text {Phos }} / \tau_{\text {Fluo }}{ }^{d}$ The radiative decay rate constant of phosphorescence $K_{\mathrm{r}}^{\text {Phos }}=\Phi_{\text {Phos }} / \tau_{\text {Phos }}$. ${ }^{e}$ The nonradiative decay rate constant of phosphorescence $K_{\mathrm{nr}}^{\mathrm{Phos}}=\left(1-\Phi_{\mathrm{Phos}}\right) / \tau_{\mathrm{Phos}}{ }^{f}{ }^{f}$ Not detected. ${ }^{g}$ Not calculated.
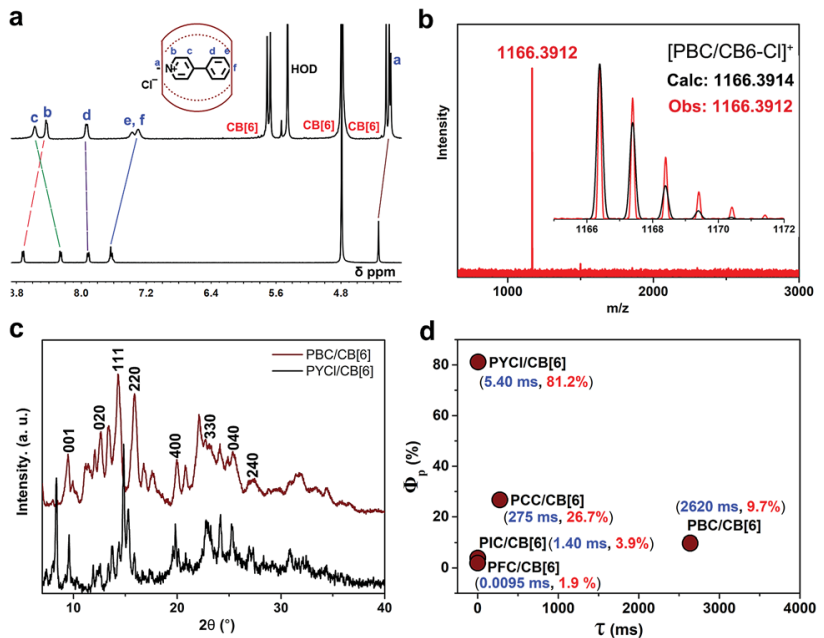

Fig. 2 (a) ${ }^{1} \mathrm{H}$ NMR spectra of $\mathrm{PBC} / \mathrm{CB}[6]$ and $\mathrm{PBC}$; (b) high resolution mass spectrometry of $\mathrm{PBC} / \mathrm{CB}[6]$; (c) XRD patterns of $\mathrm{PBC} / \mathrm{CB}[6]$ (wine) and PYCl/CB[6] (black); (d) phosphorescence quantum yield $\left(\Phi_{\mathrm{p}}\right)$ and lifetime $(\tau)$ of $\mathrm{PX} / \mathrm{CB}[6]$

$\mathrm{CB}[6]$ and $\mathrm{PC} / \mathrm{CB}[6])$ (Fig. S23 and S24†). This means that the structure of (substituted) phenylmethylpyridinium was indispensable for generating phosphorescence of the complex in these cases. The high resolution mass spectra showed an intense peak of [PX/CB6-Cl $]^{+}$, which proved the complexation between these guests and $\mathrm{CB}[6]$ (Fig. S25 $†$ ). Moreover, enormous upfield shifts of methyl protons and aromatic protons of guests further confirmed that these guests were deeply complexed by CB[6] (Fig. S26-S30†).

On the basis of the measured quantum yields and lifetimes of these complexes, the radiative and nonradiative decay rate constants could be calculated following the standard methods (Table 1). ${ }^{28,40-42}$ Eqn (1) and (2) in Scheme 1 indicated that small $K_{\mathrm{r}}^{\text {Phos }}+K_{\mathrm{nr}}^{\text {Phos }}$ was beneficial for achieving long lifetime, while high $\Phi_{\text {Phos }}$ was the comprehensive result of efficient ISC (high $\Phi_{\text {isc }}$ ) and high efficiency of phosphorescence $\left(K_{\mathrm{r}}^{\text {Phos }} /\left(K_{\mathrm{r}}^{\text {Phos }}+K_{\mathrm{nr}}^{\text {Phos }}\right)\right)$. The intersystem crossing rate constant $K_{\text {isc }}$ of complexes ranged between $1.2 \times 10^{7}$ and $2.2 \times 10^{8} \mathrm{~s}^{-1}$. The fast ISC of $\mathrm{S}_{1} \rightarrow \mathrm{T}_{n}(n \geq$ 1) $\left(1.1 \times 10^{8} \mathrm{~s}^{-1}\right.$ for $\mathrm{PCC} / \mathrm{CB}[6]$ and $2.2 \times 10^{8} \mathrm{~s}^{-1}$ for $\left.\mathrm{PYCl} / \mathrm{CB}[6]\right)$ produced a sufficient population of $\mathrm{T}_{1}$ and therefore provided one of the essential conditions for efficient phosphorescence. The slow nonradiative decay $\left(K_{\mathrm{nr}}^{\text {Phos }}=2.7 \mathrm{~s}^{-1}\right.$ for PCC/CB[6] and 34.8 $\mathrm{s}^{-1}$ for $\left.\mathrm{PYCl} / \mathrm{CB}[6]\right)$ of phosphorescence provided another one, resulting in high phosphorescence quantum yield $(81.2 \%$ for $\mathrm{PYCl} / \mathrm{CB}[6]$ and $26.7 \%$ for $\mathrm{PCC} / \mathrm{CB}[6])$. For $\mathrm{PBC} / \mathrm{CB}[6]$, the extremely low value of $K_{\mathrm{r}}^{\text {Phos }}+K_{\mathrm{nr}}^{\text {Phos }}\left(0.377 \mathrm{~s}^{-1}\right)$ made $\mathrm{T}_{1}$ deactivation a very slow process and therefore resulted in ultralong lifetime. The $K_{\mathrm{r}}^{\text {Phos }}+K_{\mathrm{nr}}^{\text {Phos }}$ of PCC/CB[6] was also small enough $\left(3.67 \mathrm{~s}^{-1}\right)$ to produce an afterglow (Fig. $1 \mathrm{c}$ and Video $\left.2 \dagger\right)$. Moreover, there was no positive correlation between the phosphorescence quantum yield $\left(\Phi_{\mathrm{Phos}}\right)$ of the complexes and the atomic number of the substituted halogen (Table 1 and Fig. S31-S33†). A possible explanation was proposed: according to eqn (2) in Scheme 1, the increase of atomic number (from $\mathrm{F}$ to I) would improve $\Phi_{\text {isc }}$ and $K_{\mathrm{r}}^{\text {Phos }}$, which was beneficial for achieving high $\Phi_{\text {Phos }}{ }^{6}$ But $K_{\mathrm{nr}}^{\mathrm{Phos}}$ would be improved too and $\Phi_{\text {Phos }}$ would decrease. Therefore, $K_{\mathrm{r}}^{\text {phos }} /\left(K_{\mathrm{r}}^{\text {Phos }}+K_{\mathrm{nr}}^{\text {phos }}\right)$ would increase or decrease, making $\Phi_{\text {Phos }}$ either higher or lower.

Information encryption and anti-counterfeiting are of great significance and have received enormous attention in this information era. ${ }^{43-49}$ On the basis of distinct lifetime and robust phosphorescence properties of these complexes, a triple encoding model was fabricated. As illustrated in Fig. 3 (dotted box), the digital pattern was painted with different complexes on flexible paper, among which $\mathrm{PYCl} / \mathrm{CB}[6]$ was used to label the black part, the dark gray part was coated with $\mathrm{PCC} / \mathrm{CB}[6]$, and the light gray part was painted with $\mathrm{PBC} / \mathrm{CB}[6]$. In daylight, only a colorless pattern was obtained. When a UV lamp with $365 \mathrm{~nm}$ excitation was turned on, an intense green "1054" appeared because of the high quantum yield of $\mathrm{PYCl} / \mathrm{CB}[6]$ (Fig. 3 and Video $3 \uparrow$ ). On switching the UV lamp off, the relatively short lifetime of $\mathrm{PYCl} / \mathrm{CB}[6](5.40 \mathrm{~ms})$ made its phosphorescence disappear immediately, while long-lived PCC/CB[6] (275 ms) and $\mathrm{PBC} / \mathrm{CB}[6]$ (2620 ms) contributed to the moderate green "6849". Later, the phosphorescence of $\mathrm{PCC} / \mathrm{CB}[6]$ became invisible, and the pattern that remained was "5213". Therefore, we achieved triple lifetime-encoding for information encryption and anticounterfeiting by subtle utilization of the diverse lifetimes of phosphorescent complexes. 


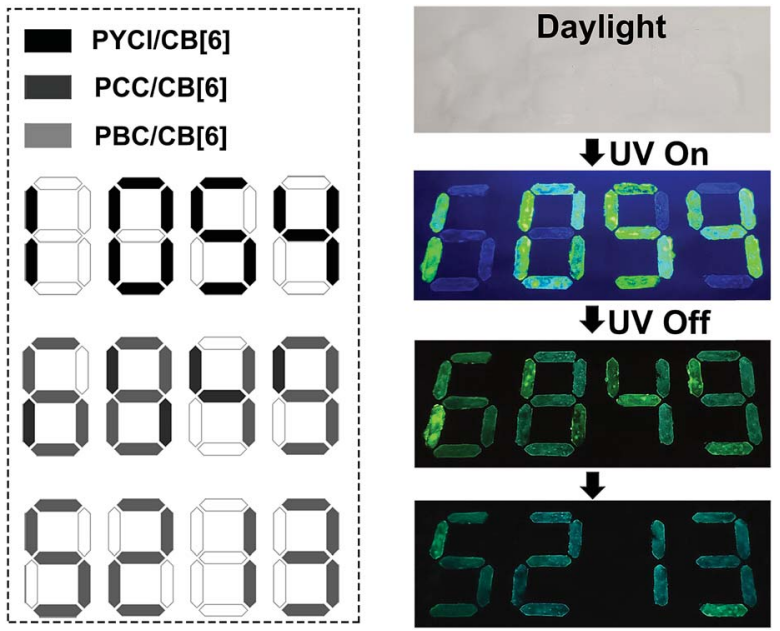

Fig. 3 Schematic illustration of lifetime-encoding for security applications using PYCl/CB[6], PCC/CB[6] and PBC/CB[6]

\section{Conclusion}

In conclusion, we present a concise and universal solid-state supramolecular strategy to realize purely organic heavy-atomfree ultralong RTP based on $\mathrm{CB}[6]$ and phenylmethylpyridinium. The strategy involving the enhancement of ISC and suppression of nonradiative decay through the complexation of $\mathrm{CB}[6]$ can remarkably promote RTP of phenylmethylpyridinium and its derivatives under ambient conditions. Significantly, $\mathrm{PBC} / \mathrm{CB}[6]$ powder exhibits a phosphorescence lifetime of $2.62 \mathrm{~s}$ and a decent efficiency of $9.7 \%$. Moreover, the structure of phenylmethylpyridinium (PBC, $\mathrm{PFC}, \mathrm{PCC}, \mathrm{PYCl}$ and PIC) is vital for the generation of phosphorescence. Notably, PBC/CB[6], PCC/CB[6] and $\mathrm{PYCl} / \mathrm{CB}[6]$ were successfully applied in triple lifetime-encoding by utilizing their different lifetimes, showing great potential for application in information encryption and anti-counterfeiting. This strategy possesses the advantages of facile preparation, universality and robust RTP without rigorous conditions such as low temperature, crystallization and deoxygenation. The result will help to understand purely organic ultralong RTP and promote the generation of better (longer lifetime, higher efficiency and more robust) RTP materials that may stimulate the development of data encryption, organic devices, bio-imaging, and so on.

\section{Conflicts of interest}

There are no conflicts to declare.

\section{Acknowledgements}

We thank the NSFC $(21432004,21672113,21772099$, and 21861132001) for financial support.

\section{Notes and references}

1 Q. Zhao, C. Huang and F. Li, Chem. Soc. Rev., 2011, 40, 25082524.
2 G. Zhang, G. M. Palmer, M. W. Dewhirst and C. L. Fraser, Nat. Mater., 2009, 8, 747.

3 X. Yang, G. Zhou and W.-Y. Wong, Chem. Soc. Rev., 2015, 44, 8484-8575.

4 S. Cai, H. Shi, J. Li, L. Gu, Y. Ni, Z. Cheng, S. Wang, W.-w. Xiong, L. Li, Z. An and W. Huang, Adv. Mater., 2017, 29, 1701244.

5 S. Xu, R. Chen, C. Zheng and W. Huang, Adv. Mater., 2016, 28, 9920-9940.

6 M. Baroncini, G. Bergamini and P. Ceroni, Chem. Commun., 2017, 53, 2081-2093.

7 R. Kabe and C. Adachi, Nature, 2017, 550, 384.

8 Y. Gong, G. Chen, Q. Peng, W. Z. Yuan, Y. Xie, S. Li, Y. Zhang and B. Z. Tang, Adv. Mater., 2015, 27, 6195-6201.

9 B. Zhou and D. Yan, Adv. Funct. Mater., 2019, 29, 1807599.

10 J. Yang, X. Zhen, B. Wang, X. Gao, Z. Ren, J. Wang, Y. Xie, J. Li, Q. Peng, K. Pu and Z. Li, Nat. Commun., 2018, 9, 840.

11 Z. Yang, Z. Mao, X. Zhang, D. Ou, Y. Mu, Y. Zhang, C. Zhao, S. Liu, Z. Chi, J. Xu, Y.-C. Wu, P.-Y. Lu, A. Lien and M. R. Bryce, Angew. Chem., Int. Ed., 2016, 55, 2181-2185.

12 T. Zhang, Z. Zhao, H. Ma, Y. Zhang and W. Z. Yuan, Chem.Asian J., 2019, 14, 884-889.

13 Z. Mao, Z. Yang, Z. Fan, E. Ubba, W. Li, Y. Li, J. Zhao, Z. Yang, M. P. Aldred and Z. Chi, Chem. Sci., 2019, 10, 179-184.

14 G. Chen, H. Feng, F. Feng, P. Xu, J. Xu, S. Pan and Z. Qian, J. Phys. Chem. Lett., 2018, 9, 6305-6311.

15 Z. He, W. Zhao, J. W. Y. Lam, Q. Peng, H. Ma, G. Liang, Z. Shuai and B. Z. Tang, Nat. Commun., 2017, 8, 416.

16 O. Bolton, K. Lee, H.-J. Kim, K. Y. Lin and J. Kim, Nat. Chem., 2011, 3, 205.

17 Z. He, H. Gao, S. Zhang, S. Zheng, Y. Wang, Z. Zhao, D. Ding, B. Yang, Y. Zhang and W. Z. Yuan, Adv. Mater., 2019, 31, 1807222.

18 T. Ogoshi, H. Tsuchida, T. Kakuta, T.-a. Yamagishi, A. Taema, T. Ono, M. Sugimoto and M. Mizuno, Adv. Funct. Mater., 2018, 28, 1707369.

19 M. S. Kwon, Y. Yu, C. Coburn, A. W. Phillips, K. Chung, A. Shanker, J. Jung, G. Kim, K. Pipe, S. R. Forrest, J. H. Youk, J. Gierschner and J. Kim, Nat. Commun., 2015, 6, 8947.

20 N. Gan, H. Shi, Z. An and W. Huang, Adv. Funct. Mater., 2018, 28, 1802657.

21 S. M. Parke, E. Hupf, G. K. Matharu, I. de Aguiar, L. Xu, H. Yu, M. P. Boone, G. L. C. de Souza, R. McDonald, M. J. Ferguson, G. He, A. Brown and E. Rivard, Angew. Chem., Int. Ed., 2018, 57, 14841-14846.

22 H. Mieno, R. Kabe, N. Notsuka, M. D. Allendorf and C. Adachi, Adv. Opt. Mater., 2016, 4, 1015-1021.

23 H. Wu, W. Chi, Z. Chen, G. Liu, L. Gu, A. K. Bindra, G. Yang, X. Liu and Y. Zhao, Adv. Funct. Mater., 2019, 29, 1807243.

24 Q. Li, M. Zhou, M. Yang, Q. Yang, Z. Zhang and J. Shi, Nat. Commun., 2018, 9, 734.

25 S. Hirata, K. Totani, T. Yamashita, C. Adachi and M. Vacha, Nat. Mater., 2014, 13, 938.

26 K. Jiang, Y. Wang, C. Cai and H. Lin, Adv. Mater., 2018, 30, 1800783. 
27 X. Chen, C. Xu, T. Wang, C. Zhou, J. Du, Z. Wang, H. Xu, T. Xie, G. Bi, J. Jiang, X. Zhang, J. N. Demas, C. O. Trindle, Y. Luo and G. Zhang, Angew. Chem., Int. Ed., 2016, 55, 9872-9876.

28 Z. An, C. Zheng, Y. Tao, R. Chen, H. Shi, T. Chen, Z. Wang, H. Li, R. Deng, X. Liu and W. Huang, Nat. Mater., 2015, 14, 685.

29 L. Bian, H. Shi, X. Wang, K. Ling, H. Ma, M. Li, Z. Cheng, C. Ma, S. Cai, Q. Wu, N. Gan, X. Xu, Z. An and W. Huang, J. Am. Chem. Soc., 2018, 140, 10734-10739.

30 Y. Shoji, Y. Ikabata, Q. Wang, D. Nemoto, A. Sakamoto, N. Tanaka, J. Seino, H. Nakai and T. Fukushima, J. Am. Chem. Soc., 2017, 139, 2728-2733.

31 Y. Su, S. Z. F. Phua, Y. Li, X. Zhou, D. Jana, G. Liu, W. Q. Lim, W. K. Ong, C. Yang and Y. Zhao, Sci. Adv., 2018, 4, eaas9732.

32 X. Ma, C. Xu, J. Wang and H. Tian, Angew. Chem., Int. Ed., 2018, 57, 10854-10858.

33 D. Li, F. Lu, J. Wang, W. Hu, X.-M. Cao, X. Ma and H. Tian, J. Am. Chem. Soc., 2018, 140, 1916-1923.

34 X. Ma, J. Wang and H. Tian, Acc. Chem. Res., 2019, 52, 738748.

35 X.-F. Wang, H. Xiao, P.-Z. Chen, Q.-Z. Yang, B. Chen, C.-H. Tung, Y.-Z. Chen and L.-Z. Wu, J. Am. Chem. Soc., 2019, 141, 5045-5050.

36 H. Ma, Q. Peng, Z. An, W. Huang and Z. Shuai, J. Am. Chem. Soc., 2019, 141, 1010-1015.

37 Z.-Y. Zhang, Y. Chen and Y. Liu, Angew. Chem., Int. Ed., 2019, 58, 6028-6032.
38 Y. Zhang, T.-Y. Zhou, K.-D. Zhang, J.-L. Dai, Y.-Y. Zhu and X. Zhao, Chem.-Asian J., 2014, 9, 1530-1534.

39 J. W. Lee, S. Samal, N. Selvapalam, H.-J. Kim and K. Kim, Acc. Chem. Res., 2003, 36, 621-630.

40 C. C. Byeon, M. M. McKerns, W. Sun, T. M. Nordlund, C. M. Lawson and G. M. Gray, Appl. Phys. Lett., 2004, 84, 5174-5176.

41 S.-J. Yoon, J. H. Kim, K. S. Kim, J. W. Chung, B. Heinrich, F. Mathevet, P. Kim, B. Donnio, A.-J. Attias, D. Kim and S. Y. Park, Adv. Funct. Mater., 2012, 22, 61-69.

42 P. C. Y. Chow, S. Albert-Seifried, S. Gélinas and R. H. Friend, Adv. Mater., 2014, 26, 4851-4854.

43 Y. Zhou, S.-T. Han, X. Chen, F. Wang, Y.-B. Tang and V. A. L. Roy, Nat. Commun., 2014, 5, 4720.

44 J. Xue, Z.-K. Zhou, Z. Wei, R. Su, J. Lai, J. Li, C. Li, T. Zhang and X.-H. Wang, Nat. Commun., 2015, 6, 8906.

45 Q. Huang, X. Mei, Z. Xie, D. Wu, S. Yang, W. Gong, Z. Chi, Z. Lin and Q. Ling, J. Mater. Chem. C, 2019, 7, 2530-2534.

46 Z. Wang, C.-Y. Zhu, S.-Y. Yin, Z.-W. Wei, J.-H. Zhang, Y.-N. Fan, J.-J. Jiang, M. Pan and C.-Y. Su, Angew. Chem., Int. Ed., 2019, 58, 3481-3485.

47 K. Jiang, Y. Wang, C. Cai and H. Lin, Chem. Mater., 2017, 29, 4866-4873.

48 M. Louis, H. Thomas, M. Gmelch, A. Haft, F. Fries and S. Reineke, Adv. Mater., 2019, 31, 1807887.

49 Q. Zhou, Z. Wang, X. Dou, Y. Wang, S. Liu, Y. Zhang and W. Z. Yuan, Mater. Chem. Front., 2019, 3, 257-264. 